\title{
Current State of Surgical Simulation Training in Otolaryngology: Systematic Review of Simulation Training Models
}

\author{
Mohamedkazim Alwani, MD*; Elhaam Bandali, MS²; Michael Larsen, BS'; \\ Taha Z. Shipchandler, MD'; Jonathan Ting, MD
}

'Department of Otolaryngology-Head and Neck Surgery, Indiana University School of Medicine, Indianapolis, Indiana, USA

${ }^{2}$ Richard M. Fairbanks School of Public Health, Indiana University Purdue University Indianapolis, Indianapolis, Indiana, USA

\begin{abstract}
Objective: To present an expansive list of otolaryngology-specific surgical simulation training models as described in Otolaryngology literature and to evaluate recent advances in simulation training in Otolaryngology.

Methods: An a prior qualitative systematic review protocol was designed. Ovid/Medline, PubMed, Embase, Web of Science, and Cochrane databases were searched from their inception with cross-referenced subject headings of otolaryngology simulation training and associated terms. Information from each study was systematically extracted and summary analysis was conducted.

Results: A total of 178 records were systematically reviewed to obtain 104 unique records of surgical simulation models (34 airway/laryngeal, 16 oncology/ facial plastics/reconstructive, 17 rhinology, 37 otology). Of the records included, only 8 simulation models were reported in or before 2004,20 reported between 2005 and 2009, 34 reported between 2010 and 2014, and 42 described in or after 2015. There were 50 synthetic, 21 computer-based, 19 animal cadaver, 6 human cadaver, and 8 hybrid models. Synthetic simulators were the most common type of simulators. A total of 18 of 50 synthetic simulators were formulated using 3D-printing.

Conclusions: Current literature shows the availability of several otolaryngology-specific simulation models that have proven beneficial in otolaryngologic surgical training. Recent advancements in manufacturing and computing technologies are contributing to a paradigm shift in surgical simulation education. With the availability of these options, there exists the potential to establish a well-structured and standardized approach to simulation activities across otolaryngology training programs.
\end{abstract}

\section{INTRODUCTION}

Despite the changing landscape of surgical education with work hour restrictions and decreased independence of trainees in clinical activities [1], most training programs uphold a traditional, dogmatic approach in training surgical residents that is based on a hierarchical, apprenticeship model. This model often presents a time-intensive learning curve that leaves trainees, who are often first responders, with limited knowledge, skills, and confidence to competently deal with clinical and surgical scenarios of varying complexity [2].

Given that surgical simulation training (SST) engages the two most important tenets of adult learning by permitting moderated practical experience in the setting of guided reflection, it holds great potential in the training of otolaryngologists [3]. Although surgical simulation activities can be resource intensive [4,5], the availability of an arena for deliberate practice in a risk-free, low stress environment is an effective way to acquire skills specific to the practice of a surgical subspecialty [6].

Simulation models remain a keystone in the design of high-yield simulation activities by providing apparatus for the acquisition of surgical skills which can then be transferred to patient care [7]. Simulation models fulfill the role of physical vessels that afford trainees an opportunity to hone their psychomotor and decision-making skills without the loom of patient risk [2].

With the exponential advancement of computing and manufacturing technologies, several simulation models and platforms have recently been developed and deployed in the training of surgical residents. On a broad scale, these simulation models can be categorized into synthetic bench models, computer-based models (virtual reality or web-based), animal models (tissue or live), and human cadaveric models [8], while a combination of any of these constitutes a hybrid model.

In this study, we aim to provide a systematically reviewed list of otolaryngology simulators that are documented in Otolaryngology literature and discuss recent updates in simulation training in the field of otolaryngology.

\section{METHODS}

\section{Study Selection}

With the assistance of an information specialist, an a priori research protocol was designed based on the Preferred Reporting Items for Systematic Reviews and Meta-Analyses (PRISMA) methodology [9]. Subsequently, a sensitive systematic review was performed to obtain as many articles from five databases namely Ovid/Medline, PubMed, Embase, Web of Science, and Cochrane. The databases were searched from their inception through July $18^{\text {th }}, 2018$. Two investigators (M.A. and M.L.) conducted the search and reviewed selected articles. Subject headings for the search included otolaryngology, otology, airway, laryngeal, rhinology, reconstructive, facial plastics, and head and neck oncology cross-referenced with the terms simulation, simulation training, and simulation models. Bibliographies were manually searched to identify studies that met inclusion criteria. Inter-investigator discordances in the review process were resolved by consensus. 


\section{Identification}

\section{8 records identified via database searches}

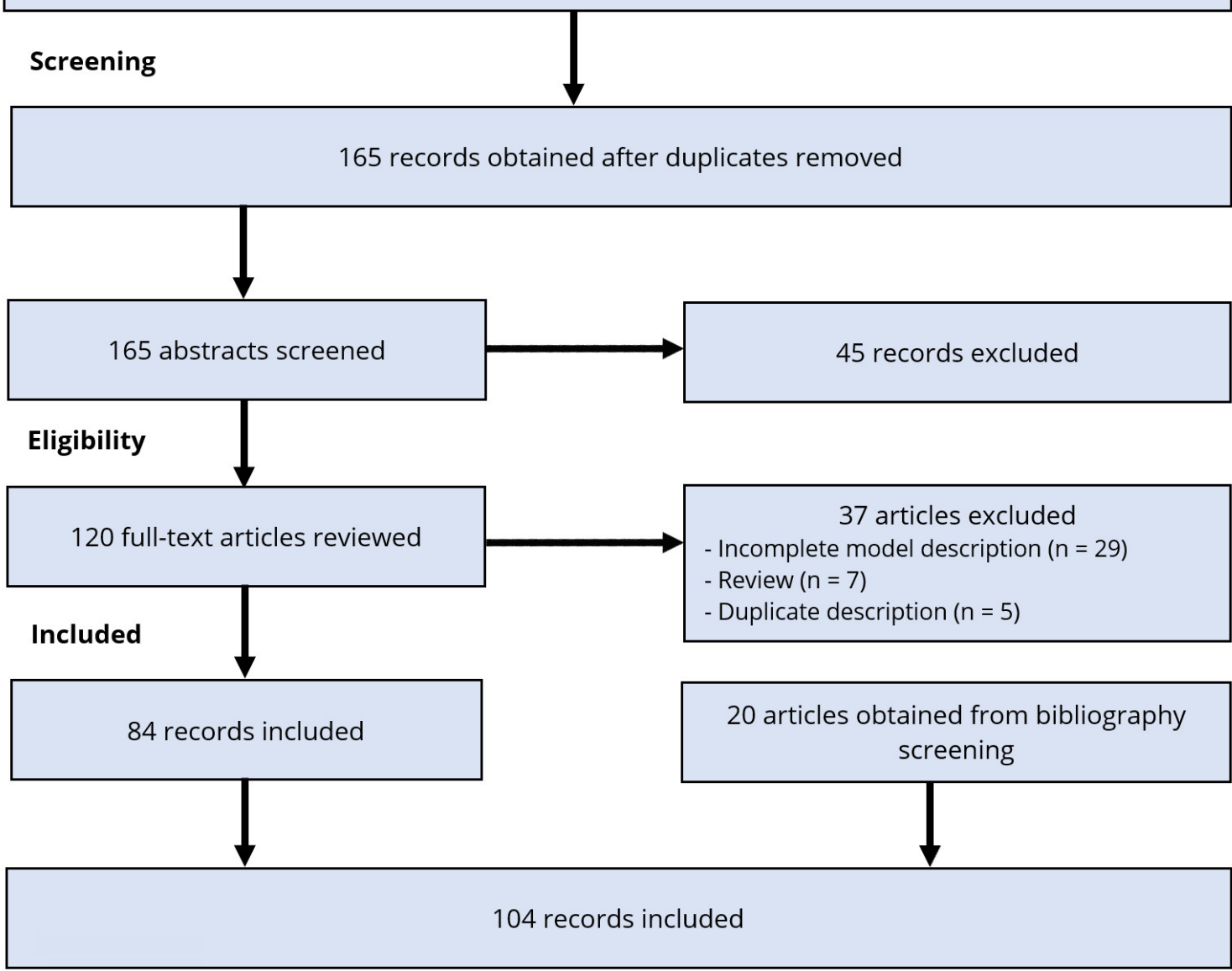

Figure 1. Systematic review flowchart based on the PRISMA methodology. PRISMA, preferred reporting items for systematic reviews and meta-analyses.

\section{Eligibility Criteria}

For the systematic review, all articles in the English literature reporting on simulation training in otolaryngology were eligible for inclusion. After elimination of duplicates, all articles were subjected to a title and abstract screen. Articles were excluded if they (1) did not report adequate data regarding the simulation model/platform, (2) did not report on otolaryngology-specific simulation, (3) were not unique (i.e., reporting simulation models already described at an earlier date in other included records), (4) were review articles not describing original simulation models and/or (5) were not reported in English language. Full texts of the remaining articles were then comprehensively reviewed. A flow chart of the systematic review design with complete numeric details is provided in Figure 1.

\section{Data Extraction and Statistical Analysis}

All data was systematically aggregated using Microsoft Excel software, version 16.12 (Microsoft). Extracted data end points included: author names, year of publication, type of simulation model, brief description of the simulation model, and key training objective of the simulation model. Data was analyzed using SPSS software, version 25 (IBM). Descriptive statistics were applied in the analysis of all studies that met inclusion criteria.

\section{RESULTS}

\section{Overall Characteristics}

The systematic review selection process and its results are captured in Figure 1. The aforementioned search strategy was applied to Ovid/Medline, PubMed, Embase, Web of Science, and Cochrane databases which yielded an output of 178 records. After elimination of duplicates, a total of 165 articles remained, which were subsequently subjected to title and abstract screening. The remaining 112 articles were subjected to comprehensive, full-text analysis. Ultimately 83 articles met final inclusion criteria. A manual bibliography screen of included articles yielded an additional 20 articles. A total of 103 records were deemed eligible for inclusion. A single record [10] was utilized as a double entry in two separate categories, yielding a grand total of 104 described otolaryngologic surgical simulation models. Of the records included, only 8 simulation models were reported in or before the year 2004, 20 were reported between 2005 and 2009, 34 models were reported between 2010 and 2014, and 42 models were described in or after the year 2015 (Figure 2). There were a total of 50 synthetic, 21 computer-based, 19 animal cadaver, 6 human cadaver, and 8 hybrid models described. Synthetic simulators were the most common type of simulators in all categories with the exception of oncology/facial plastics/ 


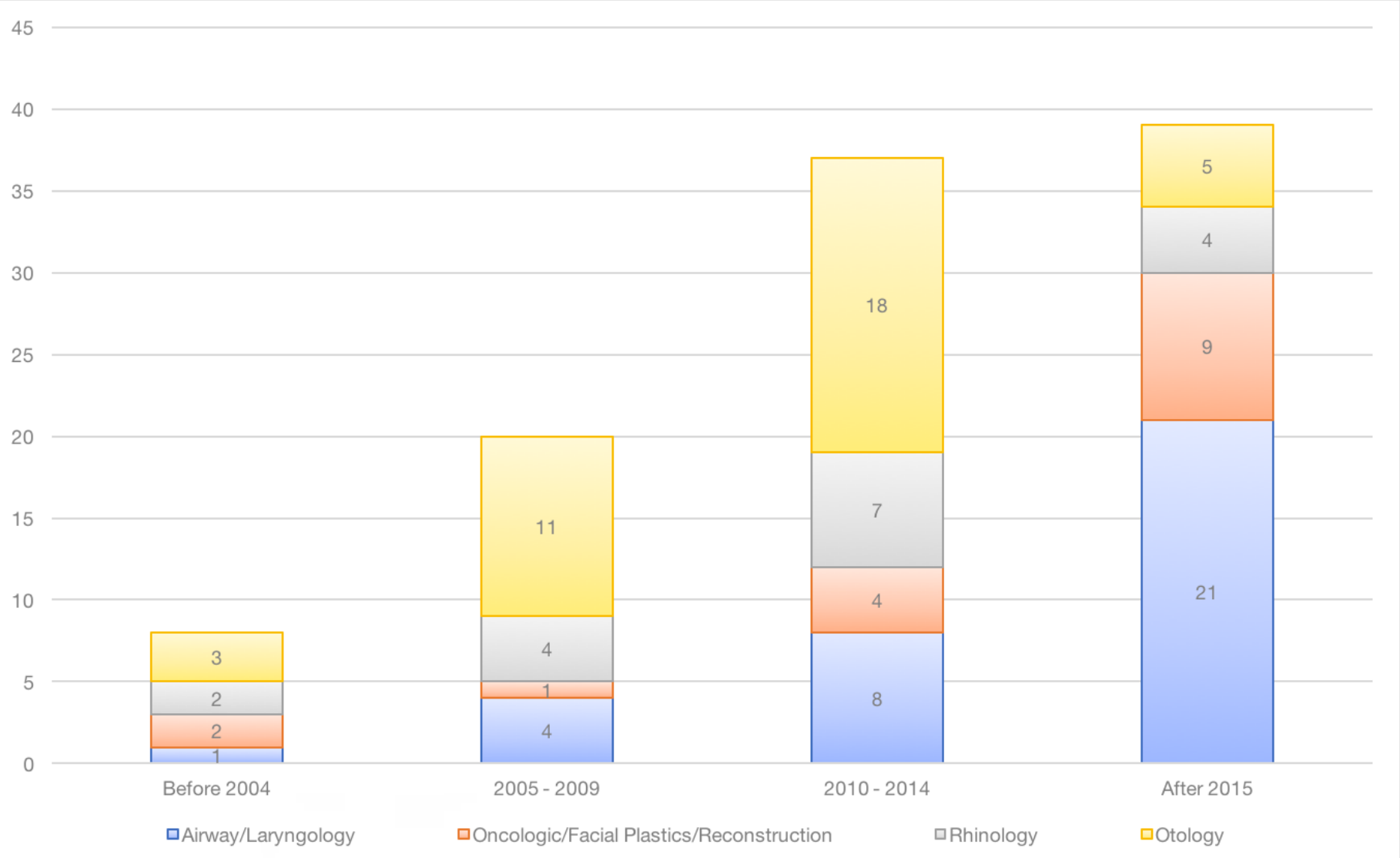

Figure 2. Number of simulation models described in literature over time.

reconstructive category, where animal cadaver models were more common. Otology had the highest number $(n=37)$ of reported simulation models while oncology/facial plastics/reconstruction had the lowest number $(n=16)$. A total of 18 of 50 synthetic simulators were purely formulated using 3D-printing techniques (36\%), with only 5 such models described prior to 2015 (27.78\%). A majority of 3D-printed synthetic simulators were described in or after the year 2015. Hybrid models most often constituted animal cadaver models combined with synthetic models (75\%), with the remainder comprised of synthetic models combined with computer-based platforms (25\%).

\section{Airway/Laryngeal Surgical Simulation Models}

A total of 34 airway and laryngeal surgical simulation models were identified (Table 1). These models consisted of 18 synthetic, 4 computer-based, 8 animal cadaver, 4 human cadaver, and 4 hybrid models. Of these 34 models, 15 models were aimed at establishing emergency surgical airways. Only 6 articles captured in our review reported on pediatric airway/laryngeal simulation models. Of all the airway/laryngeal surgical simulators, 9 models were manufactured by 3D printing $(26.47 \%)$.

\section{Oncology/Facial Plastics/Reconstruction Simulation Models}

A total of 16 oncology/facial plastics/reconstructive simulation models were identified (Table 2). These models consisted of 5 synthetic, 1 computer-based, 10 animal cadaver, and 2 hybrid models. Of the 16 simulation models, 4 were manufactured by 3D-printing (25\%). Animal cadaver models were the most common type of surgical simulation platform. Chicken cadaver parts remained the most widely reported simulation model for microvascular anastomosis training in otolaryngology literature.

\section{Rhinology}

A total of 17 rhinology surgical simulation models were identified in our systematic review (Table 3). These models consisted of 6 synthetic, 6 computer-based, 5 animal cadaver, and 2 hybrid models. Of these 17 models, 14 articles described simulation models aimed at enhancing overall skills required for Endoscopic Sinus and Skull Base Surgery (ESSS) (88\%). Only 3 out of 17 simulation models were designed for specific endoscopic tasks (12\%), and only 2 out of 17 models were manufactured by 3D-printing (11.76\%).

\section{Otology}

A total of 37 neuro-otologic simulation models were identified (Table 4). These models consisted of 21 synthetic, 12 computer-based, 2 animal cadaver, and 2 human cadaver models. All computer-based models utilized virtual reality (VR) technology except for one web-based otoscopy simulator aimed for otoscopic examination described by Wickens et al. [11]. Of these 37 models, 13 were intended for temporal bone drilling (35\%), 11 were aimed for ventilation tube insertion (30\%), and others included a variety of other ear surgical procedures. Only 3 out of 37 simulation models were manufactured by 3D-printing (8.11\%).

\section{DISCUSSION}

The implicit appeal of using simulation platforms in training is that mistakes on a simulation platform have no real-world consequences other than to serve as a marker of different degrees of task achievement [12]. Perhaps the 


\begin{tabular}{|c|c|c|c|c|}
\hline Author & Year & Type & Description of Model & Training Objective \\
\hline Ainsworth et al [18] & 2014 & Synthetic ${ }^{\dagger}$ & Laryngotracheal framework created by 3D-printing & Transcervical laryngeal injection \\
\hline Deutschmann et al [19] & 2013 & Synthetic & Hollow plastic ball with fenestrations placed inside of glove & Flexible nasolaryngoscopy \\
\hline Doucet et al [20] & 2017 & Synthetic ${ }^{\dagger}$ & 3D-printed trachea and artificial skin & Cricothyroidotomy \\
\hline Fleming et al [21] & 2012 & Synthetic & Synthetic vocal cord model in airway manikin under microscope & Phonomicrosurgery \\
\hline Gauger et al [22] & 2018 & Synthetic ${ }^{\dagger}$ & 3D-printed laryngeal model placed in manikin head & Cricothyroidotomy \\
\hline Giblett \& Hari [23] & 2016 & Synthetic & Cod liver oil tablet in tonsil mold fitted in manikin & PTA drainage \\
\hline Ha et al [24] & 2017 & Synthetic ${ }^{\dagger}$ & 3D-printed representation of harvested human costal cartilage & Airway cartilage graft carving \\
\hline Hughes et al [25] & 2018 & Synthetic ${ }^{\dagger}$ & 3D-printed trachea with two-layer silicone containing artificial blood & Bleeding cricothyroidotomy \\
\hline Jabbour et al [26] & 2011 & Synthetic ${ }^{\dagger}$ & 3D-printed organo-silicate airway replica (SimNewB) & Pediatric airway endoscopy \\
\hline Johnston et al [27] & 2015 & Synthetic & Nasolaryngopharynx model from plumbing pipes \& plastic straws & FNL \\
\hline Kavanagh et al [28] & 2016 & Synthetic ${ }^{\dagger}$ & Direct 3D-printed model versus silicone elastomer casted model & Pediatric laryngeal surgery \\
\hline Melchiors et al [29] & 2016 & Synthetic & Plastic cricoid \& laryngeal cartilage model (Airsim Advance Crico) & Cricothyroidotomy \\
\hline $\mathrm{Ng}$ et al [30] & 2018 & Synthetic & Water balloon in cup behind ballistic gelatin velopharynx & US-guided PTA drainage \\
\hline Ross et al [31] & 2008 & Synthetic & Neoprene in a potato chip tube container (Yorick's skull model) & Hemostatic tonsillar suturing \\
\hline Schwartz et al [32] & 2013 & Synthetic ${ }^{\dagger}$ & Stereolithographic models of pediatric laryngeal framework & Pediatric laryngeal surgery \\
\hline Washington et al [33] & 2014 & Synthetic & $5 \mathrm{~cm}$ plastic tubing covered by glove then toilet paper then tape & Cricothyroidotomy \\
\hline Wiebracht et al [34] & 2017 & Synthetic & Intubation trainer with disposable diverticulum inserts & Zenker's diverticulotomy \\
\hline Zambricki et al [35] & 2016 & Synthetic & Microscopic grape epithelium dissection through laryngoscope & Phonomicrosurgery \\
\hline Demirel et al [36] & 2016 & Virtual Reality & Software linked to VR goggles and haptic feedback device (VAST) & ETI and Cricothyroidotomy \\
\hline Liu et al [37] & 2005 & Virtual Reality & Hand immersive VR platform & Cricothyroidotomy \\
\hline Campbell et al [38] & 2009 & Computer + Synthetic & Pediatric manikin with interface box linked to PC (SimBaby) & Pediatric BMV/ETI/LMI \\
\hline Hesselfeldt et al [39] & 2005 & Computer + Synthetic & Adult manikin with interface box linked to PC (SimMan) & BMV/ETI/LMI \\
\hline lanacone et al [10] & 2016 & Animal cadaver & Disarticulated head and neck of pre-pubescent sheep & Cricothyroidotomy/Tracheotomy \\
\hline Isaacson et al [40] & 2015 & Animal cadaver & Disarticulated head and neck of pre-pubescent sheep & Pediatric FNL \\
\hline Isaacson et al [41] & 2016 & Animal cadaver & Disarticulated head and neck of pre-pubescent sheep & Suspension microlaryngoscopy \\
\hline Netto et al [42] & 2015 & Animal cadaver & Porcine larynx placed on wooden surface, covered with pork skin & Cricothyroidotomy \\
\hline Ram et al [43] & 1999 & Animal cadaver & Yearling porcine laryngotracheobronchial framework & Pediatric airway endoscopy \\
\hline Soliman et al [44] & 2018 & Animal cadaver & Disarticulated head and neck of sheep & Open laryngotracheal surgery \\
\hline Al-Ramahi et al [45] & 2016 & Animal cadaver + Synthetic ${ }^{\dagger}$ & Porcine and 3D-printed laryngotracheal model & Airway foreign body removal \\
\hline King et al [46] & 2016 & Animal cadaver + Synthetic & Porcine larynx placed on a plastic task trainer tray (Surgicric) & Cricothyroidotomy \\
\hline Aboud et al [47] & 2015 & Human cadaver & Perfused cadavers & ETI and Cricothyroidotomy \\
\hline Demirel et al [48] & 2016 & Human cadaver & GoPro camera recording of procedure on human cadaver & Cricothyroidotomy \\
\hline Redman et al [49] & 2018 & Human cadaver & Perfused cadaver & ETI and Cricothyroidotomy \\
\hline van Emden et al [50] & 2018 & Human cadaver & Cadaver embalmed using the F4L method & BMV/ETI/LMI \\
\hline
\end{tabular}

${ }^{\dagger}$ Models manufactured by 3D-printing. BMV, bag mask ventilation; ETI, endotracheal intubation; F4L, fixed for life; FNL, flexible nasolaryngoscopy; LMI, laryngeal mask insertion; PC, personal computer; PTA, peri-tonsillar abscess; US, ultra-sound; VAST, virtual airway simulation trainer; VR, virtual reality.

best example of the successful use of simulation in training is that of the flight simulator created by Edward Link in 1929 to train novice pilots [13]. In time, simulation-based training has grown to be the industry standard in avionics and is currently used for a variety of reasons from the training of novice pilots to flight testing of new aircraft systems [12].

The parallels to the use of simulation in surgical training are striking. With the increasing awareness of ethical concerns, complexity of surgical procedures, healthcare costs, and clinical governance, surgical trainees are faced with new-age hurdles to achieve proficiency and competency within the confines of a structured timeframe. Additionally, limited availability of time for teaching and learning due to work hour restrictions has led to a detachment from the traditional Halstedian dogma of "master and apprentice" [14]. Given that simulation provides a tool for aptitude testing, early skills acquisition, and advanced skills training [12], the development and use of surgical simulation training models have more recently gained exponent popularity as demonstrated by Figure 2. In their cross-sectional survey-based study, Deutsch et al managed to investigate interest amidst 43 US otolaryngology residency programs in advancing simulation training, with $92.9 \%$ of respondents confirming the presence of a simulation center or program at their institution and $83.8 \%$ of respondents indicating interest in participating in multi-center simulation initiatives [15]. These findings are reflective of a transition in the core philosophy of surgical education.

Historically, human and animal cadaver models and live animal models provided the mainstay raw material for simulation activities. As noted by Musbahi et al, the authors agree that it remains difficult to surpass the ability of human and animal cadaver models to provide anatomic accuracy, tissue con- 


\begin{tabular}{|c|c|c|c|c|}
\hline Author & Year & Type & Brief Description of Model/Platform & Training Objective \\
\hline Allak et al [51] & 2016 & Synthetic ${ }^{\dagger}$ & 3D-printed laryngo-esophageal superstructure & Rigid esophagoscopy \\
\hline Okamoto et al [52] & 2018 & Synthetic $^{\dagger}$ & 3D-printed bi-layered elastic model of face & Local flaps \& cheiloplasty \\
\hline Sillitoe \& Platt [53] & 2004 & Synthetic & Neoprene fabric square attached to a thermoplastic frame & Z plasty \\
\hline Taylor \& Chang [54] & 2016 & Synthetic & Artificial gelatin facial skin on polystyrene foam head & Local flaps \\
\hline Xu et al [55] & 2012 & Synthetic ${ }^{\dagger}$ & Neck mold created using 3D-printing technology & Clinical exam of neck masses \\
\hline Dworschak et al [56] & 2017 & Virtual Reality & da Vinci skills simulation software on the da Vinci surgical robot & Robotic surgical skills \\
\hline Akihiko [57] & 2003 & Animal cadaver & Chick wing vasculature & MVA \\
\hline Barber et al [58] & 2018 & Animal cadaver + Synthetic ${ }^{\dagger}$ & Squid between 3D-printed tracheal and esophageal components & TEP placement \\
\hline Chark et al [59] & 2011 & Animal cadaver & Porcine cartilage model with snout transected $4 \mathrm{~cm}$ from the tip & Nasal tip surgery \\
\hline Curry et al [60] & 2012 & Animal cadaver + Synthetic & da Vinci Si Robot used on manikin fitted with porcine tongue & TORS \\
\hline lanacone et al [10] & 2016 & Animal cadaver & Disarticulated head and neck of pre-pubescent sheep & Multiple FPR procedures \\
\hline lanacone et al [10] & 2016 & Animal cadaver & Disarticulated head and neck of pre-pubescent sheep & LTR \& Laryngectomy \\
\hline Isaacson et al [61] & 2014 & Animal cadaver & Galliform (turkey) thigh skin & Suturing and local flaps \\
\hline Khalil et al [62] & 2009 & Animal cadaver & Chicken legs with skin & Z plasty \\
\hline Pafitanis et al [63] & 2017 & Animal cadaver & Chick thigh adductor profundus & MAV \& Myocutaneous free flap \\
\hline Schoeff et al [64] & 2017 & Animal cadaver & Chicken thigh vessels & MVA \\
\hline
\end{tabular}

${ }^{\dagger}$ Models manufactured by 3D-printing. FPR, facial plastics \& reconstructive; LTR, laryngotracheal reconstruction; MVA, microvascular anastomosis; TEP, trachea-esophageal prosthesis; TORS, trans-oral robotic surgery.

\begin{tabular}{|c|c|c|c|c|}
\hline Author & Year & Type & Brief Description of Model/Platform & Training Objective \\
\hline Alrasheed et al [65] & 2017 & Synthetic ${ }^{\dagger}$ & 3D-printed sinus model placed in manikin head & ESSS \\
\hline Burge et al [66] & 2012 & Synthetic & Manikin with silicone nasal mucosa embedded with circuits & ESSS \\
\hline Leung et al [67] & 2008 & Synthetic & Metal rings, bulb drain suction, and foam & ESSS \\
\hline Malekzadeh et al [68] & 2011 & Synthetic & Ballistic gel, two eggs, \& colored beads covered by silicone manikin head & Basic ESSS \\
\hline Narayanan et al [69] & 2015 & Synthetic ${ }^{\dagger}$ & Sinonasal model created using 3D-printing & ESSS \\
\hline Nogueira et al [70] & 2008 & Synthetic & Model made of resin covered with Neoderma mucosal material (SIMONT) & ESSS \\
\hline Barber et al [71] & 2018 & Virtual Reality & Immersive VR using head mounted display with optical tracking system & ESSS \\
\hline Caversaccio et al [72] & 2003 & Virtual Reality & VR with 3D glasses, mirror, joystick, and EM stylus (Dextroscope) & ESSS \\
\hline Dharmawardana et al [73] & 2015 & Virtual Reality & Simulation software linked to haptic feedback system & ESSS \\
\hline Edmond et al [74] & 2002 & Virtual Reality & Simulation software linked to haptic feedback system (ES3) & ESSS \\
\hline Tolsdroff et al [75] & 2009 & Virtual Reality & Software paired with haptic feedback system (VOXEL-MAN SinuSurg) & ESSS \\
\hline Varshney et al [76] & 2014 & Virtual Reality & Simulation software linked to haptic devices \& pedals (MSESS) & ESSS \\
\hline Awad et al [77] & 2014 & Animal cadaver & Sheep head with shortened nose to $5 \mathrm{~cm}$ & ESSS \\
\hline Kaplan et al [78] & 2015 & Animal cadaver & Endoscopic dissection of chicken wing vasculature & Endoscopic microdissection \\
\hline Touska et al [79] & 2013 & Animal cadaver & Sheep head with shortened muzzle & ESSS \\
\hline Ogino-Nishimura et al [80] & 2012 & Animal + Synthetic & SIMONT with boiled quail egg (egg shell depicted medial orbital wall) & Orbital decompression \\
\hline Valentine et al [81] & 2016 & Animal + Synthetic & SIMONT connected to ICA of anesthetized sheep & ESSS vascular emergency \\
\hline
\end{tabular}

${ }^{\dagger}$ Models manufactured by 3D-printing. ES3, endoscopic sinus surgery simulator; ESSS, endoscopic sinus and skull base surgery; ICA, internal carotid artery; MSESS, McGill simulator for endoscopic sinus surgery; SIMONT, sinus model otorhino neuro trainer; VR, virtual reality.

sistency, and surgical conditions [8]. However, the rapid expansion and development of manufacturing and computing technologies holds the promise of delivering a paradigm shift in surgical simulation education.

As shown by our results, an ever-increasing number of anatomically accurate, customized 3D-printed models are being created as this technology becomes more available, accessible, and user-friendly. We are inclined to agree with VanKoevering and Malloy [16] in that 3D-printing provides surgical educators a unique advantage by affording an opportunity to rapidly create complex head and neck anatomical models that can be utilized for procedural training. These 3D-printed models hold an advantage over computer-based platforms because they permit tactile sensation and the use of real instruments. Given that these factors are intrinsic components in psychomotor skills training, 3D-printed models hold a distinct advantage over computer-based simulation platforms [16].

In the last five years, the arena of surgical simulation has seen a sharp increase in VR simulation platforms [17]. With the advancement in digital 3D- 


\begin{tabular}{|c|c|c|c|c|}
\hline Author & Year & Type & Brief Description of Model/Platform & Training Objective \\
\hline Awad et al [82] & 2014 & Synthetic & Malleable plaster foam model with elastic TM & Multiple otologic surgeries \\
\hline Bakhos et al [83] & 2010 & Synthetic ${ }^{\dagger}$ & 3D-printed synthetic temporal bone & TBD \\
\hline Barber et al [84] & 2016 & Synthetic ${ }^{\dagger}$ & 3D-printed middle ear dome interfacing with EAC + donuts/pegs task trainers & TEES \\
\hline Campisi et al [85] & 2011 & Synthetic & Anatomic ear canal model with distal screen to display otoscopic findings (OtoSim) & Otoscopic examination \\
\hline Carr \& Benjamin [86] & 2006 & Synthetic & $2 \mathrm{~mL}$ syringe EAC with rubber glove TM placed in 'surgical skills box' & VTI \\
\hline Duijvestein et al [87] & 2005 & Synthetic & 2 ear specula in series with silicone/latex strip stretched over smaller specula (BGT) & VTI \\
\hline Hochman et al [88] & 2013 & Synthetic ${ }^{\dagger}$ & 3D-printed synthetic temporal bone & TBD \\
\hline Hong et al [89] & 2014 & Synthetic & UHMWP base connected to syringes \& Vinyl gloves & VTI \\
\hline Jesudason \& Smith [90] & 2005 & Synthetic & Two auricular temperature probe covers assembled in series & VTI \\
\hline Leong et al [91] & 2006 & Synthetic & Plastic cylinder fitted over Vinyl on a $2.5 \mathrm{~mL}$ glass bottle & VTI \\
\hline Luu et al [92] & 2017 & Synthetic & Base unit with inserts, cigarette paper or glove for TM (The Ear Trainer) & Ear foreign body removal \\
\hline Malekzadeh et al [93] & 2011 & Synthetic & $3 \mathrm{~mL}$ syringe with plastic glove embedded mounted in a glove box & VTI \\
\hline Mathews et al [94] & 1997 & Synthetic & Tongue depressor placed through slits in a disposable cup with toothpick incus & Stapes prosthesis placement \\
\hline Morris et al [95] & 2012 & Synthetic & Manikin head with auricles, EAC, and cartridge with TM and mesotympanum & Pneumatic otoscopy \\
\hline Okada et al [96] & 2010 & Synthetic & Acrylic and resin replica mould & TBD \\
\hline Owa et al [97] & 2003 & Synthetic & $2 \mathrm{~mL}$ syringe EAC, paper TM, and $21 \mathrm{G}$ cannula incus placed in a paper basin & Stapes prosthesis placement \\
\hline Pichichero \& Poole [98] & 2001 & Synthetic & Manikin head with auricles, EAC \& TM cartridge & VTI \\
\hline Singh et al [99] & 2005 & Synthetic & Tape over end of Shah ventilation tube container & VTI \\
\hline Torgerson et al [100] & 2007 & Synthetic & Drilling on a saw bone block & TBD \\
\hline Volksy et al [101] & 2009 & Synthetic & Plastic canal component and plastic cartridge simulating TM \& mesotympanum & VTI \\
\hline Walker et al [102] & 2006 & Synthetic & 2 pieces of oxygen tubing in series with cellophane over one end of proximal piece (WT) & VTI \\
\hline Arora et al [103] & 2012 & Virtual Reality & 3D glasses + software linked to haptic feedback system (VOXEL-MAN TempoSurg) & TBD \\
\hline Arora et al [104] & 2014 & Virtual Reality & 3D glasses + software linked to haptic feedback system (VOXEL-MAN TempoSurg) & Case-specific TBD \\
\hline Fang et al [105] & 2014 & Virtual Reality & Computer software linked to force-feedback hand stylus & TBD \\
\hline Ho et al [106] & 2012 & Virtual Reality & Computer software linked to 3D stereo visor and haptic arm & Myringotomy \\
\hline Huang et al [107] & 2015 & Virtual Reality & Computer software linked to silver screen mirror viewed with 3D glasses + haptic arm & VTI \\
\hline O’Leary et al [108] & 2008 & Virtual Reality & 3D glasses + software linked to haptic feedback system (CSIRO/UOMVRTBS) & TBD \\
\hline Sorensen et al [109] & 2009 & Virtual Reality & Simulation software linked to haptic feedback system (Visible Ear Simulator) & TBD \\
\hline Sowerby et al [110] & 2010 & Virtual Reality & Computer software linked to 3D stereo visor and haptic arm & Myringotomy \\
\hline Wheeler et al [111] & 2010 & Virtual Reality & Visor viewed with 3D mock microscope stereo-headset + optical tracking system & Myringotomy \\
\hline Wickens et al [11] & 2015 & Web Based & Web-based otoscopy simulator (OtoTrain) & Otoscopic examination \\
\hline Wiet et al [112] & 2012 & Virtual Reality & Microscope + software linked to haptic feedback system (OSUVTBS) & TBD \\
\hline Zhao et al [113] & 2010 & Virtual Reality & Microscope + software linked to haptic feedback system (MSDS) & TBD \\
\hline Garcia et al [114] & 2014 & Animal cadaver & Porcine temporal bone & TBD \\
\hline Gocer et al [115] & 2007 & Animal cadaver & Transcanal access to middle ear of fresh sheep head & Transcanal stapedectomy \\
\hline Awad et al [116] & 2015 & Human cadaver & Human cadaver temporal bone for modified radical mastoidectomy & TBD \\
\hline Mowry \& Hansen [117] & 2014 & Human cadaver & Human cadaver temporal bone for transcochlear approach and jugular bulb dissection & TBD \\
\hline
\end{tabular}

${ }^{+}$Models manufactured by 3D-printing. BGT, Bradford Grommet Trainer; CSIRO/UOMVRTBS, Commonwealth Scientific and Industrial Research Organization/University of Melbourne virtual reality temporal bone simulator; EAC, external auditory canal; MSDS, Mediseus Surgical Drilling Simulator; OSUVTBS, Ohio State University virtual temporal bone simulator; TBD, temporal bone drilling; TEES, transcanal endoscopic ear surgery; TM, tympanic membrane; UHMWP, ultra-high molecular weight plastic; VR, virtual reality; VTI, ventilation tube insertion; WT, Wigan grommet trainer. 
visualization along with haptic sensory technology, VR simulation models are providing a more interactive experience than ever before. Our findings are in line with the findings of Arora et al in that VR simulators appear to be most commonly employed in the subspecialties of rhinology and otology [17].

Although prior review articles have attempted to provide a database of otolaryngologic simulation models, the recent rapid increase in the number of documented simulation models warranted an updated review of otolaryngology simulation models. To the best of our knowledge, our paper presents the most expansive database of otolaryngology-specific simulation models, such that we report a total of 104 simulation models compared to the 60 models reported by Javia et al. [118] and the 64 models reported by Musbahi et al [8]. Additionally, in contrast to works such as that of Bhutta et al. [119] and Chan et al. [120], our article discusses simulation models in all divisions of otolaryngology, rather than addressing simulation training in only a single otolaryngologic sub-specialty. Our article also serves as the first to describe otolaryngology-specific simulators under a dedicated Oncologic/Facial Plastics/Reconstruction category in addition to other more commonly described categories such as Airway/Laryngeal, Pediatric, Rhinology, and Otology.

Due to the vast and ever-growing number of documented simulation models, the systematic review performed may not have captured a comprehensive list of all available surgical simulators. Evaluation of quality and validity of individual simulation platforms was also not conducted given that this be beyond the scope of this paper. The data presented by the authors is instead intended to provide an expansive list that contains simulation options that would adequately suffice the breadth of otolaryngologic training for medical students and residents alike. Future projects can be geared towards the expansion and validity testing of this dynamic and constantly growing list, and utilize it to create a standard, uniform, cost-effective, and high-fidelity simulation curriculum that can be employed by otolaryngology training programs.

\section{CONCLUSION}

Current literature shows the availability of several otolaryngology-specific simulation models that have proven beneficial in otolaryngologic surgical training. Recent advancements in manufacturing and computing technologies are contributing to a paradigm shift in surgical simulation education. With the availability of these options, there exists the potential to establish a well-structured and standardized approach to simulation activities across otolaryngology training programs.

\section{ARTICLE INFORMATION}

*Correspondence: Mohamedkazim Alwani, MD, Department of Otolaryngology-Head and Neck Surgery, Indiana University Health, Suite 400, Fesler Hall, 1130 West Michigan Street, Indianapolis, Indiana 46202, Indiana, USA. Email: malwani@iupui.edu

Received: Mar. 07, 2019; Accepted: Mar. 20, 2019; Published: Apr. 03, 2019

DOI: 10.24983/scitemed.aohns.2019.00109

Disclosure: Podium presentation at 2019 Triological Combined Sections Meeting Coronado, CA, Jan 24-26, 2019

Ethics Approval and Consent to Participate: The study is in accordance with the ethical standards of the 1964 Helsinki declaration and its later amendments or comparable ethical standards.

Funding: The study did not receive any specific grant from funding agencies in the public, commercial, or not-for-profit sectors.

Conflict of Interest: The authors report no financial or other conflict of interest relevant to this article, which is the intellectual property of the authors.

Copyright @ 2019 The Authors. This is an open-access article distributed under the terms of the Creative Commons Attribution 4.0 International License (CC-BY).

\section{REFERENCES}

1. Calman KC, Temple JG, Naysmith R, Cairncross RG, Bennett SJ. Reforming higher specialist training in the united kingdom--a step along the continuum of medical education. Med Educ 1999;33(1):28-33.

2. Malekzadeh S, Malloy KM, Chu EE, Tompkins J, Battista A, Deutsch ES. Orl emergencies boot camp: Using simulation to onboard residents. Laryngoscope 2011;121(10):2114-2121.

3. Zigmont JJ, Kappus LJ, Sudikoff SN. Theoretical foundations of learning through simulation. Semin Perinatol 2011;35(2):47-51.

4. Michelson JD, Manning L. Competency assessment in simulation-based procedural education. Am J Surg 2008;196(4):609-615.

5. McClusky DA, 3rd, Smith CD. Design and development of a surgical skills simulation curriculum. World J Surg 2008;32(2):171-181.

6. Sonnadara RR, Van Vliet A, Safir O, et al. Orthopedic boot camp: Examining the effectiveness of an intensive surgical skills course. Surgery 2011;149(6):745-749.

7. Sturm LP, Windsor JA, Cosman PH, Cregan P, Hewett PJ, Maddern GJ. A systematic review of skills transfer after surgical simulation training. Ann Surg 2008;248(2):166-179.

8. Musbahi O, Aydin A, Al Omran Y, Skilbeck CJ, Ahmed K. Current status of simulation in otolaryngology: A systematic review. J Surg Educ 2017;74(2):203-215.

9. Moher D, Liberati A, Tetzlaff J, Altman DG, Group P. Preferred reporting items for systematic reviews and meta-analyses: The prisma statement. Int J Surg 2010;8(5):336-341.

10. Ianacone DC, Gnadt BJ, Isaacson G. Ex vivo ovine model for head and neck surgical simulation. Am J Otolaryngol 2016;37(3):272-278.

11. Wickens B, Lewis J, Morris DP, Husein M, Ladak HM, Agrawal SK. Face and content validity of a novel, web-based otoscopy simulator for medical education.J Otolaryngol Head Neck Surg 2015;44(1):7.

12. Dawson S. Procedural simulation: A primer. Radiology 2006;241(1):17-25.

13. Abou-Elhamd KE, Al-Sultan Al, Rashad UM. Simulation in ent medical education. J Laryngol Otol 2010;124(3):237-241.

14. Wiet GJ, Stredney D, Wan D. Training and simulation in otolaryngology. Otolaryngol Clin North Am 2011;44(6):1333-1350, viii-ix.

15. Deutsch ES, Wiet GJ, Seidman M, Hussey HM, Malekzadeh S, Fried MP. Simulation activity in otolaryngology residencies. Otolaryngol Head Neck Surg 2015;153(2):193-201.

16. VanKoevering KK, Malloy KM. Emerging role of three-dimensional printing in simulation in otolaryngology. Otolaryngol Clin North Am 2017;50(5):947-958.

17. Arora A, Lau LY, Awad Z, Darzi A, Singh A, Tolley N. Virtual reality simulation training in otolaryngology. Int J Surg 2014;12(2):87-94.

18. Ainsworth TA, Kobler JB, Loan GJ, Burns JA. Simulation model for transcervical laryngeal injection providing real-time feedback. Ann Otol Rhinol Laryngol 2014;123(12):881-886.

19. Deutschmann MW, Yunker WK, Cho Jj, Andreassen M, Beveridge S, Bosch JD. Use of a low-fidelity simulator to improve trans-nasal fibre-optic flexible laryngoscopy in the clinical setting: A randomized, single-blinded, prospective study. J Otolaryngol Head Neck Surg 2013;42(1):35.

20. Doucet G, Ryan S, Bartellas M, Parsons M, Dubrowski A, Renouf T. Modelling and manufacturing of a $3 \mathrm{~d}$ printed trachea for cricothyroidotomy simulation. Cureus 2017;9(8):e1575.

21. Fleming J, Kapoor K, Sevdalis N, Harries M. Validation of an operating room immersive microlaryngoscopy simulator. Laryngoscope 2012;122(5):1099-1103.

22. Gauger VT, Rooney D, Kovatch $\mathrm{KJ}$, et al. A multidisciplinary international collaborative implementing low cost, high fidelity $3 \mathrm{~d}$ printed airway models to enhance ethiopian anesthesia resident emergency cricothyroidotomy skills. Int J Pediatr Otorhinolaryngol 2018;114:124-128.

23. Giblett N, Hari C. Introducing a realistic and reusable quinsy simulator. J Laryngol Otol 2016;130(2):201-203.

24. Ha JF, Morrison RJ, Green GE, Zopf DA. Computer-aided design and 3-dimensional printing for costal cartilage simulation of airway graft carving. Otolaryngol Head Neck Surg 2017;156(6):1044-1047.

25. Hughes KE, Biffar D, Ahanonu EO, Cahir TM, Hamilton A, Sakles JC. Evaluation of an innovative bleeding cricothyrotomy model. Cureus 2018;10(9):e3327.

26. Jabbour N, Reihsen T, Sweet RM, Sidman JD. Psychomotor skills training in pediatric airway endoscopy simulation. Otolaryngol Head Neck Surg 2011;145(1):43-50.

27. Johnston DI, Selimi V, Chang A, Smith M. A low-cost alternative for nasolaryngoscopy simulation training equipment: A randomised controlled trial. J Laryngol Otol 2015;129(11):1101-1107.

28. Kavanagh KR, Cote V, Tsui Y, Kudernatsch S, Peterson DR, Valdez TA. Pediatric laryngeal simulator using $3 \mathrm{~d}$ printed models: A novel technique. Laryngoscope 2017;127(4):E132-E137.

29. Melchiors J, Todsen T, Nilsson P, et al. Self-directed simulation-based training of 
emergency cricothyroidotomy: A route to lifesaving skills. Eur Arch Otorhinolaryngol 2016;273(12):4623-4628.

30. Ng V, Plitt J, Biffar D. Development of a novel ultrasound-guided peritonsillar abscess model for simulation training. West J Emerg Med 2018;19(1):172-176.

31. Ross SK, Jaiswal V, Thomas S. Re: Yorick's skull model for tonsillectomy tie training. Clin Otolaryngol 2008;33(6):630-631.

32. Schwartz MA, Kavanagh KR, Frampton SJ, Bruce IA, Valdez TA. Using simulators to teach pediatric airway procedures in an international setting. Int J Pediatr Otorhinolaryngol 2018;104:178-181.

33. Washington $\mathrm{CH}$, Tyler FJ, Davis J, et al. Trauma training course: Innovative teaching models and methods for training health workers in active conflict zones of eastern myanmar. Int J Emerg Med 2014;7(1):46.

34. Wiebracht ND, Giliberto JP, Myer Ct, Casper K, Johnson KE. Pilot testing of a novel surgica simulator for endoscopic zenker's diverticulotomy. Laryngoscope 2017;127(3):592-596.

35. Zambricki EA, Bergeron JL, DiRenzo EE, Sung CK. Phonomicrosurgery simulation: A low-cost teaching model using easily accessible materials. Laryngoscope 2016;126(11):2528-2533.

36. Demirel D, Yu A, Halic T, et al. Virtual airway skills trainer (vast) simulator. Stud Health Technol Inform 2016;220:91-97.

37. Liu A, Bhasin Y, Bowyer M. A haptic-enabled simulator for cricothyroidotomy. Stud Health Technol Inform 2005;111:308-313.

38. Campbell DM, Barozzino T, Farrugia M, Sgro M. High-fidelity simulation in neonatal resuscitation. Paediatr Child Health 2009;14(1):19-23.

39. Hesselfeldt R, Kristensen MS, Rasmussen LS. Evaluation of the airway of the simman full-scale patient simulator. Acta Anaesthesio/ Scand 2005;49(9):1339-1345.

40. Isaacson G, lanacone DC, Wolfson MR. Ex vivo ovine model for pediatric flexible endoscopy training. Int J Pediatr Otorhinolaryngo/ 2015;79(12):2196-2199.

41. Isaacson G, lanacone DC, Soliman AM. Ex vivo ovine model for suspension microlaryngoscopy training. J Laryngol Otol 2016;130(10):939-942.

42. Netto FA, Zacharias P, Cipriani RF, Constantino Mde M, Cardoso M, Pereir RA. A porcine model for teaching surgical cricothyridootomy. Rev Col Bras Cir 2015;42(3):193-196

43. Ram B, Oluwole M, Blair RL, Mountain R, Dunkley P, White PS. Surgical simulation: An animal tissue model for training in therapeutic and diagnostic bronchoscopy.J Laryngol Otol 1999;113(2):149-151.

44. Soliman AMS, lanacone DC, Isaacson GC. Ex vivo ovine model for teaching open laryngotracheal surgery. World J Otorhinolaryngol Head Neck Surg 2018;4(2):140-144.

45. Al-Ramahi J, Luo H, Fang R, Chou A, Jiang J, Kille T. Development of an innovative 3d printed rigid bronchoscopy training model. Ann Otol Rhinol Laryngol 2016;125(12):965-969.

46. King W, Teare J, Vandrevala T, Cartwright S, Mohammed KB, Patel B. Evaluation of a novel surgicric( $r$ cricothyroidotomy device for emergency tracheal access in a porcine model. Anaesthesia 2016;71(2):177-184.

47. Aboud ET, Aboud G, Aboud T. "Live cadavers" for practicing airway management. Mil Med 2015;180(3 Suppl):165-170.

48. Demirel D, Butler KL, Halic T, et al. A hierarchical task analysis of cricothyroidotomy procedure for a virtual airway skills trainer simulator. Am J Surg 2016;212(3):475-484

49. Redman TT, Ross EM. A novel expeditionary perfused cadaver model for trauma training in the out-of-hospital setting. J Emerg Med 2018;55(3):383-389.

50. van Emden MW, Geurts JJ, Schober P, Schwarte LA. Comparison of a novel cadaver model (fix for life) with the formalin-fixed cadaver and manikin model for suitability and realism in airway management training. Anesth Analg 2018;127(4):914-919.

51. Allak A, Liu YE, Oliynyk MS, Weng KH, Jameson MJ, Shonka DC, Jr. Development and evaluation of a rigid esophagoscopy simulator for residency training. Laryngoscope 2016;126(3):616-619.

52. Okamoto T, Hirota Y, Kimura Y, Senda E, Ueda K. 3d separable 2-layered elastic models of the face for surgical planning of local flaps. Plast Reconstr Surg Glob Open 2018;6(7):e1857.

53. Sillitoe AT, Platt A. The z-plasty simulator. Ann R Coll Surg Eng/ 2004;86(4):304-305.

54. Taylor SR, Chang CW. Gelatin facial skin simulator for cutaneous reconstruction. Otolaryngol Head Neck Surg 2016;154(2):279-281.

55. $\mathrm{Xu}$ ل ال Fung K, Glicksman JT, Brandt MG, Campbell G. Development of a tissue-mimicking neck model for medical education. J Otolaryngol Head Neck Surg 2012;41(2):145-151.

56. Walliczek-Dworschak $U$, Schmitt M, Dworschak $P$, et al. The effect of different training exercises on the performance outcome on the da vinci skills simulator. Surg Endosc 2017;31(6):2397-2405.

57. Hino A. Training in microvascular surgery using a chicken wing artery. Neurosurgery 2003;52(6):1495-1498
58. Barber SR, Kozin ED, Naunheim MR, Sethi R, Remenschneider AK, Deschler DG. 3d-printed tracheoesophageal puncture and prosthesis placement simulator. Am J Otolaryngol 2018;39(1):37-40.

59. Chark D, Oliaei S, Manuel C, Wong BJ. Porcine cartilage model for simulation of nasal tip aesthetics and mechanics. Aesthet Surg J 2011;31(5):501-505.

60. Curry M, Malpani A, Li R, et al. Objective assessment in residency-based training for transoral robotic surgery. Laryngoscope 2012;122(10):2184-2192.

61. Isaacson DS, Edmonds PR, Isaacson G. The galliform (turkey thigh) model for resident training in facial plastic surgery. Laryngoscope 2014;124(4):866-868.

62. Khalil PN, Siebeck M, Mutschler W, Kanz KG. The use of chicken legs for teaching wound closure skills. European Journal of Medical Research 2009;14(10):459.

63. Pafitanis G, Serrar Y, Raveendran M, Ghanem A, Myers S. The chicken thigh adductor profundus free muscle flap: A novel validated non-living microsurgery simulation training model. Arch Plast Surg 2017;44(4):293-300.

64. Schoeff S, Hernandez B, Robinson DJ, Jameson MJ, Shonka DC, Jr. Microvascular anastomosis simulation using a chicken thigh model: Interval versus massed training. Laryngoscope 2017;127(11):2490-2494.

65. Alrasheed AS, Nguyen LHP, Mongeau L, Funnell WRJ, Tewfik MA. Development and validation of a 3d-printed model of the ostiomeatal complex and frontal sinus for endoscopic sinus surgery training. Int Forum Allergy Rhinol 2017;7(8):837-841.

66. Burge SD, Bunegin L, Weitzel EK, McMains KC. The validation of an endoscopic sinus surgery skills training model: A pilot study. Am J Rhinol Allergy 2012;26(5):409-413.

67. Leung RM, Leung J, Vescan A, Dubrowski A, Witterick I. Construct validation of a low-fidelity endoscopic sinus surgery simulator. Am J Rhinol 2008;22(6):642-648.

68. Malekzadeh S, Pfisterer MJ, Wilson B, Na H, Steehler MK. A novel low-cost sinus surgery task trainer. Otolaryngol Head Neck Surg 2011;145(4):530-533.

69. Narayanan V, Narayanan P, Rajagopalan R, et al. Endoscopic skull base training using $3 \mathrm{~d}$ printed models with pre-existing pathology. Eur Arch Otorhinolaryngol 2015;272(3):753-757.

70. Nogueira JF, Stamm AC, Lyra M, Balieiro FO, Leao FS. Building a real endoscopic sinus and skull-base surgery simulator. Otolaryngol Head Neck Surg 2008;139(5):727-728.

71. Barber SR, Jain S, Son YJ, Chang EH. Virtual functional endoscopic sinus surgery simulation with 3d-printed models for mixed-reality nasal endoscopy. Otolaryngol Head Neck Surg 2018;159(5):933-937.

72. Caversaccio M, Eichenberger A, Häusler R. Virtual simulator as a training tool for endonasal surgery. American Journal of Rhinology 2003;17(5):283-290.

73. Dharmawardana N, Ruthenbeck G, Woods C, et al. Validation of virtual-reality-based simulations for endoscopic sinus surgery. Clin Otolaryngol 2015;40(6):569-579.

74. Edmond CV, Jr. Impact of the endoscopic sinus surgical simulator on operating room performance. Laryngoscope 2002;112(7 Pt 1):1148-1158.

75. Tolsdorff B, Pommert A, Hohne $\mathrm{KH}$, et al. Virtual reality: A new paranasal sinus surgery simulator. Laryngoscope 2010;120(2):420-426.

76. Varshney R, Frenkiel S, Nguyen LH, et al. Development of the mcgill simulator for endoscopic sinus surgery: A new high-fidelity virtual reality simulator for endoscopic sinus surgery. Am J Rhinol Allergy 2014;28(4):330-334.

77. Awad Z, Touska P, Arora A, Ziprin P, Darzi A, Tolley NS. Face and content validity of sheep heads in endoscopic rhinology training. Int Forum Allergy Rhinol 2014;4(10):851-858.

78. Kaplan DJ, Vaz-Guimaraes F, Fernandez-Miranda JC, Snyderman CH. Validation of a chicken wing training model for endoscopic microsurgical dissection. Laryngoscope 2015;125(3):571-576

79. Touska P, Awad Z, Tolley NS. Suitability of the ovine model for simulation training in rhinology. Laryngoscope 2013;123(7):1598-1601.

80. Ogino-Nishimura E, Nakagawa T, Sakamoto T, Ito J. An endoscopic endonasal surgery training model using quail eggs. Laryngoscope 2012;122(10):2154-2157.

81. Valentine R, Padhye V, Wormald PJ. Simulation training for vascular emergencies in endoscopic sinus and skull base surgery. Otolaryngol Clin North Am 2016:49(3):877-887.

82. Awad Z, Ahmed S, Taghi AS, et al. Feasibility of a synthetic temporal bone for training in mastoidectomy: Face, content, and concurrent validity. Otol Neurotol 2014;35(10):1813-1818

83. Bakhos D, Velut S, Robier A, Al zahrani M, Lescanne E. Three-dimensional modeling of the temporal bone for surgical training. Otol Neurotol 2010;31(2):328-334.

84. Barber SR, Kozin ED, Dedmon M, et al. 3d-printed pediatric endoscopic ear surgery simulator for surgical training. Int J Pediatr Otorhinolaryngol 2016;90:113-118.

85. Campisi P, Tirado Y, Chadha NK, Forte V. Otoscopy simulation: A new paradigm in undergraduate medical education. The Laryngoscope 2011;121(S5):S246.

86. Carr ER, Benjamin E. 'Surgical skills box': A new training aid for surgical trainees. J Laryngol Otol 2006;120(2):133-134.

87. Duijvestein $M$, Borgstein J. The bradford grommet trainer. Clin Otolaryngol 2006;31(2):163. 
88. Hochman JB, Kraut J, Kazmerik K, Unger BJ. Generation of a 3d printed temporal bone model with internal fidelity and validation of the mechanical construct. Otolaryngol Head Neck Surg 2014;150(3):448-454.

89. Hong P, Webb AN, Corsten G, et al. An anatomically sound surgical simulation model for myringotomy and tympanostomy tube insertion. Int J Pediatr Otorhinolaryngol 2014;78(3):522-529.

90. Jesudason WV, Smith I. How we do it: The bradford grommet trainer: A model for training in myringotomy and grommet insertion. Clin Otolaryngol 2005;30(4):371-373.

91. Leong A, Kundu S, Martinez-Devesa P, Aldren C. Artificial ear: A training tool for grommet insertion and manual dexterity. ORL J Otorhinolaryngol Relat Spec 2006;68(2):115-117.

92. Luu K, Straatman L, Nakku D, Westerberg B, Carter N, Clark M. Evaluation of a low-fidelity ear surgery simulator in a low-resource setting. J Laryngol Otol 2017;131(11):1010-1016.

93. Malekzadeh S, Hanna G, Wilson B, Pehlivanova M, Milmoe G. A model for training and evaluation of myringotomy and tube placement skills. Laryngoscope 2011;121(7):1410-1415.

94. Mathews SB, Hetzler DG, Hilsinger RL, Jr. Incus and stapes footplate simulator Laryngoscope 1997;107(12 Pt 1):1614-1616.

95. Morris E, Kesser BW, Peirce-Cottler S, Keeley M. Development and validation of a novel ear simulator to teach pneumatic otoscopy. Simul Healthc 2012;7(1):22-26.

96. Okada DM, Sousa AMAd, Huertas RdA, Suzuki FA. Surgical simulator for temporal bone dissection training. Brazilian Journal of Otorhinolaryngology 2010;76(5):575-578.

97. Owa AO, Gbejuade HO, Giddings C. A middle-ear simulator for practicing prosthesis placement for otosclerosis surgery using ward-based materials. J Laryngol Otol 2003;117(6):490-492.

98. Pichichero ME, Poole MD. Assessing diagnostic accuracy and tympanocentesis skills in the management of otitis media. Arch Pediatr Adolesc Med 2001;155(10):1137-1142.

99. Singh PK, De M, Vaughan-Jones R. A model for training in grommet insertion. Ann R Coll Surg Eng/ 2005;87(4):287-288.

100. Torgerson C, Brydges R, Chen J, Dubrowski A. Low fidelity simulation of tempora bone drilling leads to improved but suboptimal outcomes. Stud Health Technol Inform 2007;125:470-472.

101. Volsky PG, Hughley BB, Peirce SM, Kesser BW. Construct validity of a simulator for myringotomy with ventilation tube insertion. Otolaryngol Head Neck Surg 2009;141(5):603-608 e601.

102. Walker T, Duvvi S, Kumar BN. The wigan grommet trainer. Clin Otolaryngol 2006;31(4):349-350.

103. Arora A, Khemani S, Tolley N, et al. Face and content validation of a virtual reality temporal bone simulator. Otolaryngol Head Neck Surg 2012;146(3):497-503.

104. Arora A, Swords C, Khemani S, et al. Virtual reality case-specific rehearsal in temporal bone surgery: A preliminary evaluation. Int J Surg 2014;12(2):141-145.
105. Fang TY, Wang PC, Liu CH, Su MC, Yeh SC. Evaluation of a haptics-based virtual reality temporal bone simulator for anatomy and surgery training. Comput Methods Programs Biomed 2014;113(2):674-681.

106. Ho AK, Alsaffar H, Doyle PC, Ladak HM, Agrawal SK. Virtual reality myringotomy simulation with real-time deformation: Development and validity testing. Laryngoscope 2012;122(8):1844-1851.

107. Huang C, Cheng H, Bureau Y, Agrawal SK, Ladak HM. Face and content validity of a virtual-reality simulator for myringotomy with tube placement. J Otolaryngol Head Neck Surg 2015;44(1):40.

108. O'Leary SJ, Hutchins MA, Stevenson DR, et al. Validation of a networked virtual reality simulation of temporal bone surgery. Laryngoscope 2008;118(6):1040-1046.

109. Sorensen MS, Mosegaard J, Trier P. The visible ear simulator: A public pc application for gpu-accelerated haptic $3 d$ simulation of ear surgery based on the visible ear data. Otol Neurotol 2009;30(4):484-487.

110. Sowerby LJ, Rehal G, Husein M, Doyle PC, Agrawal S, Ladak HM. Development and face validity testing of a three-dimensional myringotomy simulator with haptic feedback. J Otolaryngol Head Neck Surg 2010;39(2):122-129.

111. Wheeler B, Doyle PC, Chandarana S, Agrawal S, Husein M, Ladak HM. Interactive computer-based simulator for training in blade navigation and targeting in myringotomy. Comput Methods Programs Biomed 2010;98(2):130-139.

112. Wiet GJ, Stredney D, Kerwin T, et al. Virtual temporal bone dissection system: Osu virtual temporal bone system: Development and testing. Laryngoscope 2012;122 Suppl 1(S1):S1-12.

113. Zhao YC, Kennedy G, Yukawa K, Pyman B, O'Leary S. Can virtual reality simulator be used as a training aid to improve cadaver temporal bone dissection? Results of a randomized blinded control trial. Laryngoscope 2011;121(4):831-837.

114. Garcia LdB, Andrade JSCd, Testa JRG. Anatomical study of the pigs temporal bone by microdissection. Acta Cirurgica Brasileira 2014;29(suppl 3):77-80

115. Gocer C, Eryilmaz A, Genc U, Dagli M, Karabulut H, Iriz A. An alternative model for stapedectomy training in residency program: Sheep cadaver ear. Eur Arch Otorhinolaryngol 2007;264(12):1409-1412.

116. Awad Z, Tornari C, Ahmed S, Tolley NS. Construct validity of cadaveric temporal bones for training and assessment in mastoidectomy. Laryngoscope 2015;125(10):2376-2381.

117. Mowry SE, Hansen MR. Resident participation in cadaveric temporal bone dissection correlates with improved performance on a standardized skill assessment instrument. Otol Neurotol 2014;35(1):77-83.

118. Javia L, Deutsch ES. A systematic review of simulators in otolaryngology. Otolaryngol Head Neck Surg 2012;147(6):999-1011.

119. Bhutta MF. A review of simulation platforms in surgery of the temporal bone. Clin Otolaryngol 2016;41(5):539-545.

120. Chan M, Carrie S. Training and assessment in functional endoscopic sinus surgery. J Laryngol Otol 2018;132(2):133-137. 